Article

\title{
Hygrothermal Performance of Worship Spaces: Preservation, Comfort, and Energy Consumption
}

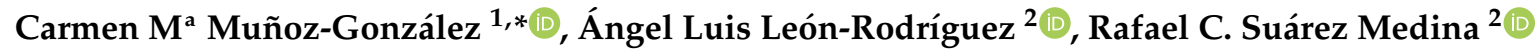 \\ and Catherine Teeling ${ }^{3}$ (I) \\ 1 Departamento de Arte y Arquitectura., Escuela Técnica Superior de Arquitectura de Málaga, \\ Universidad de Málaga, Plaza del Ejido 2, 29013 Málaga, Spain \\ 2 Instituto Universitario de Arquitectura y Ciencias de la Construcción, Escuela Técnica Superior de \\ Arquitectura, Universidad de Sevilla, Av. de Reina Mercedes 2, 41012 Seville, Spain; leonr@us.es (Á.L.L.-R.); \\ rsuarez@us.es (R.C.S.M.) \\ 3 Creative and Cultural Industries, Department Portsmouth School of Architecture, University of Portsmouth, \\ Eldon Building, Winston Churchill Avenue, Portsmouth PO1 2DJ, UK; Catherine.teeling@port.ac.uk \\ * Correspondence: carmenmgonzalez@uma.es or carmenmgonzalez@us.es; Tel.: +34-654-460-339
}

Received: 2 September 2018; Accepted: 19 October 2018; Published: 23 October 2018

check for updates

\begin{abstract}
The energy problem, one the most important on a global scale, greatly affects the environment. Much of the current energy consumption occurs in existing buildings, including heritage buildings with varying protected status. Energy intervention and heritage conservation conflict to some extent, as research focuses more on the search for improved energy efficiency solutions for materials and systems than on their application to heritage buildings. This study describes experimental research on environmental conditioning techniques in spaces of worship in a temperate climate in southern Spain. Buildings were monitored and assessed in the implementation of different environmental techniques_-active and combined (passive and active)—with the aim of improving the thermal comfort conditions of the faithful while preserving the cultural heritage of these buildings. The need for a control system of RH and the air system was concluded, as well as radiant floors and radiators, which, in the considered case studies, would barely affect the artworks. 24- and 12-h operation are better suited to heritage preservation than occasional use. All operation schedules are valid for thermal comfort.
\end{abstract}

Keywords: cultural heritage; energy consumption; preservation; comfort; HVAC; worship spaces; movable heritage

\section{Introduction}

In most Christian cities, churches are some of the most representative historic buildings. Most churches, no matter their size, have great architectural and artistic value, as well as extensive movable heritage. Sacred liturgical objects and works of art as important as those found in museums are often found in these spaces. However, in most cases there is no permanent technical and administrative framework for the conservation of these objects, despite the fact that many of these are included in the General Registry of Objects of Cultural Interest or the General Inventory of Movable Objects [1].

For centuries, climate has been a conditioning factor in the interior hygrothermal conditions of churches. Although most of these buildings originally lacked thermal conditioning systems, some rudimentary examples could be found in certain cold weather regions [2]. Nevertheless, these spaces increasingly incorporate heating and cooling systems [3] for improving comfort conditions for occupants. The application of these systems is often indiscriminate, with no prior study on hygrothermal modifications [4] with the potential to critically affect the conservation of these buildings and any artworks within them [5]. 
Thermal comfort conditions in these heritage buildings tend to conflict with their conservation, making it necessary to reach a compromise [6]. These spaces are also characterised by a large volume of air and construction systems of high thermal inertia. Due to the high energy consumption of the active conditioning systems implemented, sustainability and energy efficiency have become major considerations in the implementation of environmental conditioning techniques. Consequently, it becomes necessary to select strategies and air conditioning systems with low energy demand and environmental impact $[7,8]$.

For economic reasons, and given their generally intermittent occupation, most churches with Heating Ventilation Air Conditioning Systems (HVAC) use them only for limited periods of time, coinciding with events with audiences. However, this strategy of intermittent and occasional air conditioning can have adverse effects on the conservation of the building and its contents [9].

A physical and quantitative analysis of the complex interaction between indoor air conditions, the structural composition of the building, and occupant comfort is needed in order to control interior hygrothermal conditions. To this end, the environmental performance of many of these spaces is currently being monitored and assessed $[10,11]$.

At present, simulation software for the calculation of environmental conditions and energy consumption in buildings is extremely useful for predicting the behaviour of the different climate conditioning systems and facilities [12]. However, as this type of software is geared towards the evaluation of more modern buildings, the results obtained for heritage buildings can be less accurate [13]. Therefore, monitoring and real measurements are needed in order to validate and contrast the results obtained from the simulation. Onsite measurements make it possible to generate simulation models with behaviour close to reality [14].

Analysis of the scientific literature shows that several aspects of the research on environmental evaluation are related to preventive conservation and thermal comfort and contribute to striking a balance with the requirements of preservation and enhancement of the heritage. However, there are no energy assessment schemes specific to historic buildings [15]. Recently, the European legislation on energy efficiency of buildings focused on this topic, encouraging the reduction of $\mathrm{CO}_{2}$ emissions, increased the use of renewable sources and the retrofitting of existing buildings [16]. Although historic buildings are spared the application of energy legislation, in the case of buildings like these this can lead to major changes in the appearance of cultural assets. Furthermore, the HVAC systems contemplated in current regulations can be used to provide thermal comfort for occupants and/or to improve indoor climate conditions for conservation. In addition, the most common strategies for heating spaces of worship follow (general or localised) spatial distribution, either continuous or intermittent. While the majority of scientific research is carried out in cold climates, the case of the Spanish churches in the Mediterranean climate differs greatly from that of the churches in northern Europe. In this temperate climate, heating demand is much lower in winter, while in spring and summer the demand for cooling and dehumidification is greater due to the high temperatures and outdoor humidity.

The main aim of this research is quantification and evaluation through monitoring and simulation models of the hygrothermal parameters of three churches in southern Spain, (Mediterranean climate) following the combined implementation of active environmental techniques (HVAC) and passive techniques for reducing energy consumption. Moreover, their impact on the preservation of property, thermal occupant comfort, and energy consumption are also analysed simultaneously in order to obtain references about the case study located in a temperate climate.

\section{Methodology}

This research was developed following an experimental method combining analytical formulations and in-situ experimental measurements with simulation techniques to predict the hygrothermal behaviour of religious spaces. As well as examining the influence of these constructive systems and HVAC systems on energy consumption, work was carried out to condition the spaces of 
worship in a Mediterranean climate, considering three basic aspects: heritage preservation (to avoid biological degradation and mechanical damage), thermal comfort, and energy efficiency.

\subsection{Monitoring}

Simultaneous measurements were carried out and infrared images obtained in the churches at fifteen-minute intervals over a year. The protocols set in UNE-EN ISO 7726:2002 [17] and UNE-EN 1558 were followed when installing the monitoring system [18].

To obtain representative climate data, combined digital air humidity and temperature sensors (USB data loggers) were placed at the best possible locations avoiding the influence of radiating sources, air flow through door openings, and heat loss through external walls or barrel vaults. Temperature, relative humidity, and dew point were measured and recorded in a range of -35 to $80{ }^{\circ} \mathrm{C}$ and $0 \%$ to $100 \%$, with an accuracy of $\pm 0.3{ }^{\circ} \mathrm{C}$ and a resolution of $0.03{ }^{\circ} \mathrm{C}$. In the case of $\mathrm{RH}$, this is $\pm 2 \%$, with a resolution of $0.05 \%$. Outdoor air temperature, $\mathrm{RH}$, wind, and pressure were measured at a meteorological station near the church. The meteorological data for global radiation and cloud cover were obtained from the Morón de la Frontera station.

Multifunction measurement equipment was used to assess the quality of indoor ambient air, ventilation, etc. Measurements were carried out in different summer and winter periods, over a monitoring period lasting one year.

Infrared image measurements were performed following the image recording procedure detailed in EN 13187 [19], while the measurement of the reflected apparent temperature (reflector method) followed ISO 18434-1 [20]. The infrared images obtained provided (two-dimensional) global representation of the interior surface temperatures of individual churches and were subsequently compared using simulation programs and the ThermaCAM B4 FLIR infrared camera (FLIR Systems, Wilsonville, OR, USA), with a thermal resolution of $320 \times 240$ pixels.

\subsection{Computational Modelling}

The second phase consisted of modelling environmental and energy simulation using DesignBuilder 5, EnergyPlus 8.6 software [21] by the US Department of Energy (DOE) to simulate heat transfer processes and HVAC in buildings. Simulation models generated reproduced the interior and exterior of the churches, as well as constructive conditions and materials, in order to predict the environmental behaviour of different passive and active systems, as well as energy consumption. These models were validated using monitoring data. The models of the churches consist of three areas: the nave and the chapels on the ground floor and the roof of the barrel vault.

To evaluate the offset between the in-situ results and the values obtained through simulations, two statistical measurement indicators [22] were used, as recommended in ASHRAE 14-2014 [23]: Hourly Mean Bias Error (MBE) and Coefficient of Variation of the Root Mean Square Error CV(RMSE).

In addition, MATLAB was used to calculate PMV (Predicted Mean Vote) and PPD (Predicted percentage of dissatisfied) values following Fanger.

\subsection{Environmental Conditioning Hypotheses}

Validation models were used to simulate different environmental conditioning techniques and to evaluate the environmental impact of the implementation of active systems (HVAC) — both individually and combined with passive techniques-in the preservation of heritage, human comfort, and energy consumption. Previous research used passive techniques to examine the issue of thermal comfort and preservation in churches. It was concluded that retrofitting proposals that only use passive environmental techniques do not completely eliminate mechanical risks or the biodeterioration of the materials inherent to movable heritage $[9,12,22]$.

Several hygrothermal conditioning strategies have been proposed: 
- Heating and cooling systems without humidifier: full air autonomous system (H1) and air handling unit (AHU) (H2)

- Heating and cooling systems with humidifier: Air handling unit AHU (H3), or combined with air handling unit (AHU) and heating with radiators (H4) or radiant flooring (H5).

- Ventilation system without temperature control but no humidifier (H6), or with humidifier (H7).

The active and passive systems in these study cases will be implemented into secondary structures or church furniture with the aim of respecting the architectural and historical value of these churches and guaranteeing reversibility.

In order to determine the potential energy saving due to action on constructive elements, active systems were combined with passive techniques (HP), including nine hypotheses on control of temperature and relative humidity (H8 to $\mathrm{H} 15)$ and with relative humidity control alone (H16).

The passive techniques examined were: HP3, addition of thermal insulation to flooring; HP5, increased thermal insulation in the barrel vault (to implement thermal material on extrados of vault), addition of thermal insulation to flooring and change from single glazing to double glazing (double window); HP6, increased thermal insulation in the barrel vault and in blank walls (thermal insulation with paint), addition of thermal insulation to flooring and change from single glazing to double glazing (Table 1).

Table 1. Study hypotheses. ${ }^{*}$ ) System without dehumidification control.

\begin{tabular}{|c|c|c|c|}
\hline \multirow[t]{2}{*}{ Hypothesis } & \multirow[t]{2}{*}{ Description } & \multicolumn{2}{|c|}{ Control } \\
\hline & & $\mathrm{T}$ & RH \\
\hline Passive & $\begin{array}{l}\text { HP0: Change from single glazing to double glazing }\left(\mathrm{U} \text { windows }=2.42 \mathrm{~W} / \mathrm{m}^{2} \mathrm{~K}\right) \\
\text { HP1: Increased thermal insulation in the barrel vault }\left(\mathrm{U} \text { barrel } \mathrm{v}=0.80 \mathrm{~W} / \mathrm{m}^{2} \mathrm{~K}\right) \\
\text { HP2: Increased thermal insulation in blank walls }\left(\mathrm{U} \text { wall }=0.63 \mathrm{~W} / \mathrm{m}^{2} \mathrm{~K}\right) \\
\text { HP3: Addition of thermal insulation to flooring }\left(\mathrm{U} \text { floor }=1.50 \mathrm{~W} / \mathrm{m}^{2} \mathrm{~K}\right) \\
\text { HP4: HP0+HP1+HP2 } \\
\text { HP5: HP0+HP1+HP3 } \\
\text { HP4: HP0+HP1+HP2 } \\
\text { HP6: HP0+HP1+HP2+HP3 }\end{array}$ & NO & NO \\
\hline \multirow{7}{*}{ Active (HVAC) } & H1: Full air autonomous system (heating + cooling) & YES & $\mathrm{NO}$ \\
\hline & H2: Air handling unit (AHU) (heating + cooling) & YES & NO \\
\hline & H3: AHU (heating + cooling) + humidifier & YES & YES \\
\hline & H4: AHU (cooling) + humidifier + radiators (heating) & YES & YES \\
\hline & H5: AHU (cooling) + humidifier + radiant flooring (heating) & YES & YES \\
\hline & H6: Ventilation & NO & NO \\
\hline & H7: Ventilation + humidifier & NO & YES $(*)$ \\
\hline \multirow{9}{*}{$\begin{array}{c}\text { Combined } \\
\text { (Passive }+ \text { active })\end{array}$} & H8: (H3 + HP3) AHU + humidifier+ insulated flooring & YES & YES \\
\hline & H9: (H4 + HP3) AHU + humidifier+ radiators + insulated flooring & YES & YES \\
\hline & H10: (H3 + HP5) AHU + humidifier + d.glazing + insul. Vault + insulated flooring & YES & YES \\
\hline & H11: (H4 + HP5) AHU + humid. + radiators + window + insul. Vault + insul.flooring & YES & YES \\
\hline & H12: $(\mathrm{H} 5+\mathrm{HP5}) \mathrm{AHU}+$ humid. + rad. flooring + window + in. vault + in..flooring & YES & YES \\
\hline & H13: (H3 + HP6) AHU + humid. + window + vault + wall + flooring & YES & YES \\
\hline & H14: (H4 + HP6) AHU + humid. + radiators + window + vault + walls + flooring & YES & YES \\
\hline & H15: (H5 + HP6) AHU + humid. + rad. flooring + window + vault+ walls + flooring & YES & YES \\
\hline & H16: (H7 + HP6) Ventilation + humid. + window + vault + walls + flooring & $\mathrm{NO}$ & YES $\left(^{*}\right)$ \\
\hline
\end{tabular}

Different operation modes were simulated: continuous conditioning $(24 \mathrm{~h})$; another for a daytime period (12 h), from 9:00 a.m. to 9:00 p.m.; and finally, occasional use (use) where the building is usually in free evolution and heated only during acts of worship.

The operating conditions required for facilities are shown in Tables 2 and 3. The requirements followed were those of the Spanish Regulation of Thermal Installations in Buildings (RITE) [24], setting the thermal comfort conditions for a rational use of energy, in addition to conservation requirements UNE-EN-15759-1 [5], UNE-EN 15758 [18], and ASHRAE [25]. 
Table 2. Indoor design conditions.

\begin{tabular}{ccc}
\hline COMFORT (RITE) & T & RH \\
\hline Winter & $21-23^{\circ} \mathrm{C}$ & $40-50 \%$ \\
Summer & $23-25^{\circ} \mathrm{C}$ & $45-60 \%$ \\
Preservation & & \\
Winter & $10-20^{\circ} \mathrm{C}$ & $30-65 \%$ \\
Summer & $20-30{ }^{\circ} \mathrm{C}$ & $30-60 \%$ \\
\hline
\end{tabular}

Table 3. Ranges established for the active conditioning systems.

\begin{tabular}{cccc}
\hline Winter & Spring & Summer & Autumn \\
\hline $20^{\circ} \mathrm{C}$ & $23^{\circ} \mathrm{C}$ & $25^{\circ} \mathrm{C}$ & $23^{\circ} \mathrm{C}$ \\
$45-65 \%$ & $45-65 \%$ & $45-65 \%$ & $45-65 \%$ \\
\hline
\end{tabular}

\subsection{Risk Analysis}

Biological degradation, mechanical risk, thermal comfort, and energy consumption are evaluated based on the different control systems and operation modes.

Biological degradation is the disintegration of materials due to the effects of bacteria, fungi, etc. These case studies were analysed both in their initial state and after the use of HVAC systems, in order to establish the influence of the implementation of environmental techniques on the proliferation of insects and attacks from hylotropes and lotuses. Temperature and relative humidity levels are established when $\mathrm{T}$ and $\mathrm{RH}$ are in the growth range. $\mathrm{T}<20^{\circ} \mathrm{C}$ and $\mathrm{RH}>65 \%$ can encourage the appearance of these insects according to D. Erhardt [26].

Mechanical degradation is connected with changes in $\mathrm{RH}$, and to a lesser extent $\mathrm{T}$, which cause materials to shrink and expand. These occur when $\Delta \mathrm{T} \geq 2{ }^{\circ} \mathrm{C}$ according to ASHRAE [25] and $\Delta \mathrm{RH} \geq$ $10 \%$ according to UNE-EN 15757 [4].

EN-ISO 7730 is applied in order to determine the range of thermal comfort requirements [27]. A limitation of thermal comfort is proposed in a range from neutral sensation to slightly cool, that is to say, with the Predicted Mean Vote (PMV) between +1 and -1 .

\section{Case Studies}

The methodology defined above was applied to three churches in Morón de la Frontera (Seville), declared Assets of Cultural Interest in the Monument category. These churches were built in the proto-baroque style in the mid-16th and 17th centuries, with similar volumes and constructive systems but different floor plans. (Figure 1).

Although the three buildings were originally built freestanding on the outskirts of the town, various side chapels have been added over time. As a result of urban growth, these churches have now been surrounded by other buildings, some of which are adjoining to the walls of the church (Figure 1).

Two of the churches (SF and V) are composed of a single rectangular nave, while that of $N^{\text {a }}$ Señora de la Merced Church (M) presents a Latin cross plan. All have thick stone and brick walls, with barrel vaults or wood panelled ceilings (Figure 1). A wide variety of artworks can be found in all three churches, including wooden altarpieces, sculptures, and frescoes. Table 4 shows the basic data for each church, as well as the composition, thickness, and thermal transmittance of the main building elements of the envelope. 


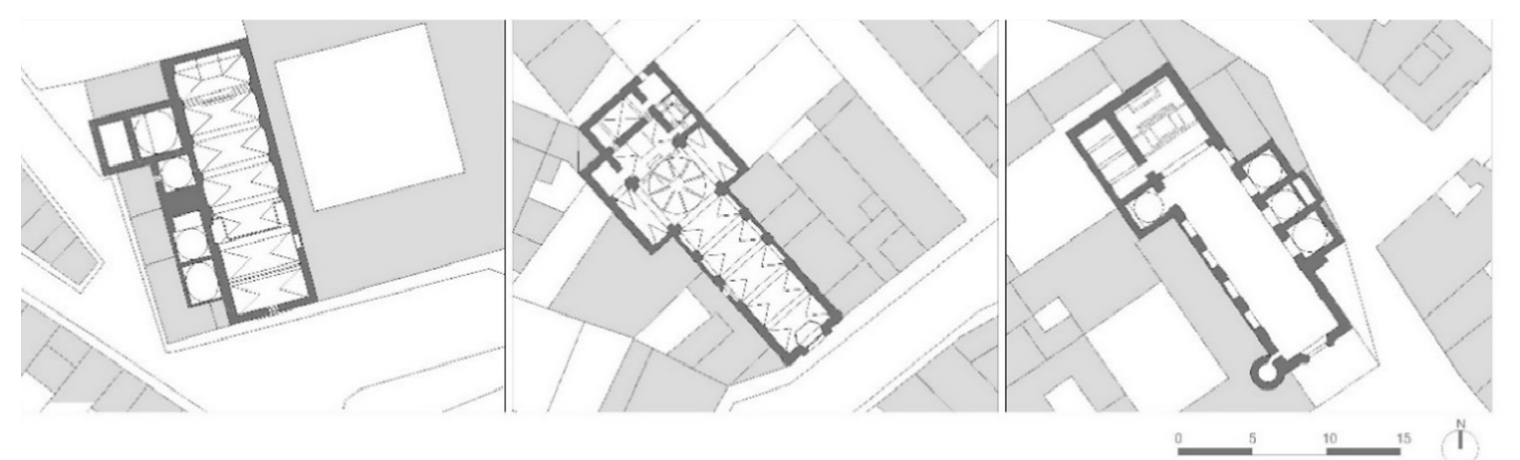

(SF) Church of San Francisco de Asís
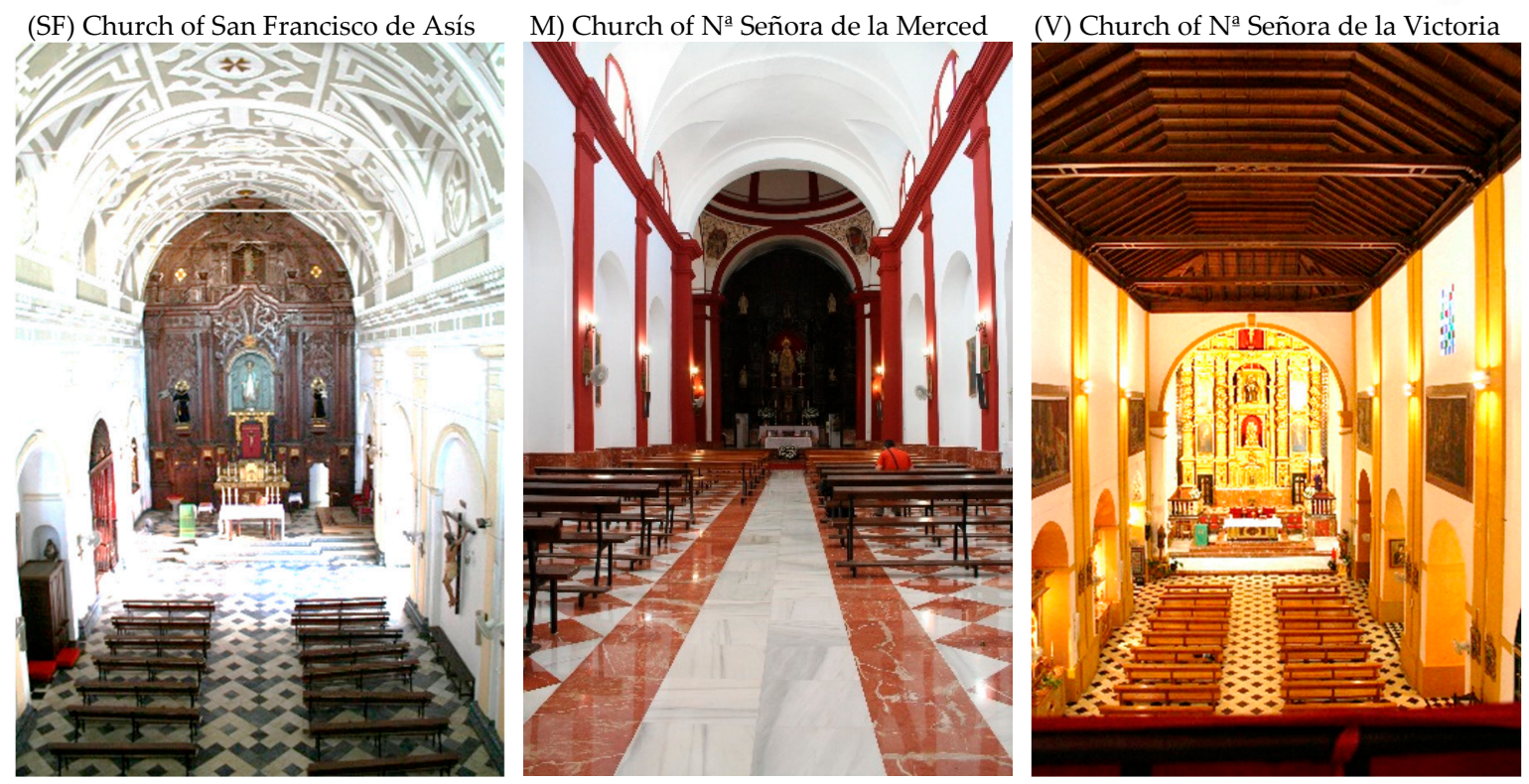

Figure 1. Interior plans and pictures for the churches studied. (SF) San Francisco de Asís Church, (M) $\mathrm{N}^{\mathrm{a}}$ Señora de la Merced Church, and (V) $\mathrm{N}^{\mathrm{a}}$ Señora de la Victoria church. 
Table 4. Physical properties of buildings.

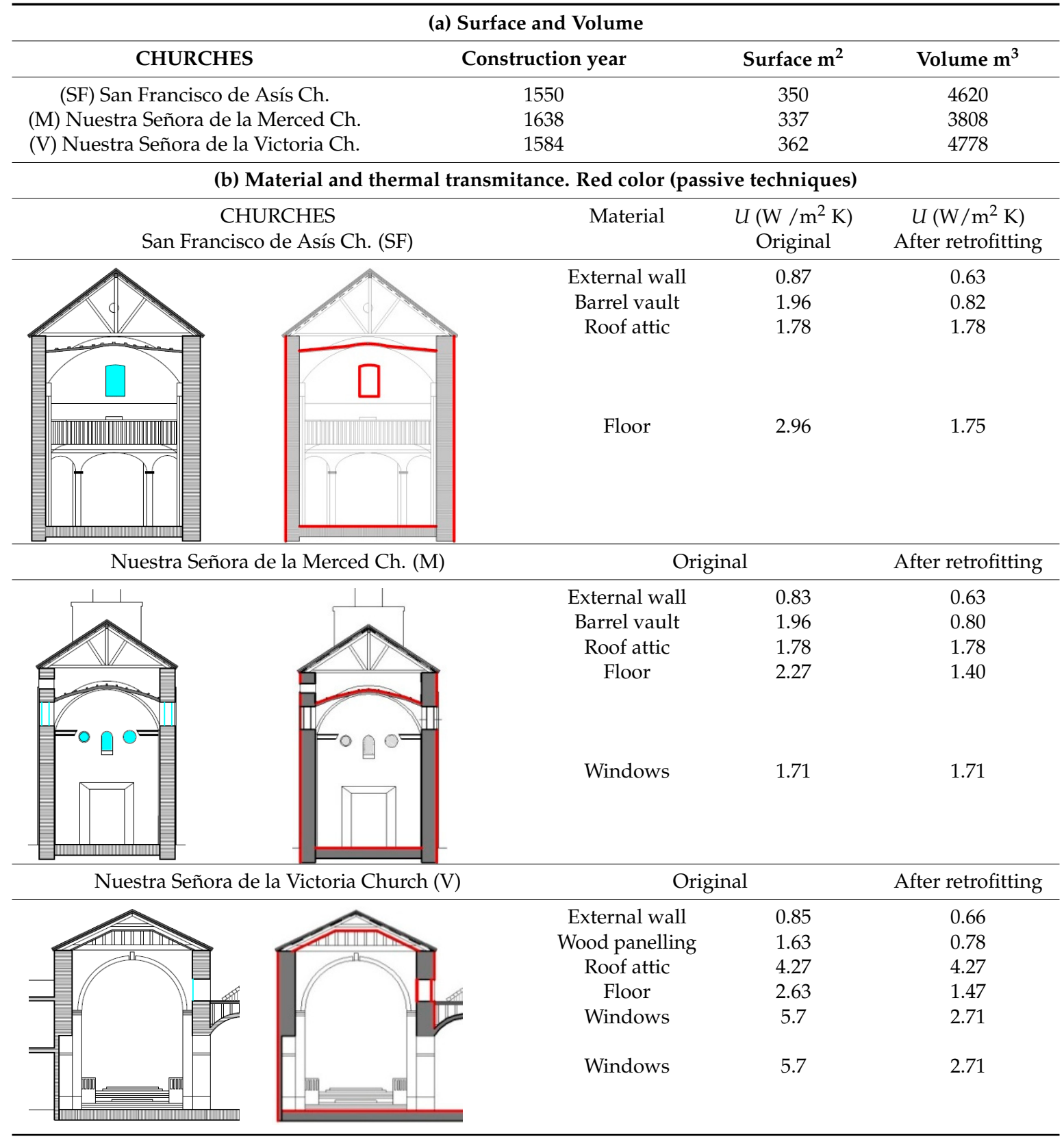

\subsection{Monitoring and Measurements In Situ}

Sensors were placed on walls to record values of the overall behaviour of the interior space as accurately as possible. These sensors were selected according to the different orientation and height of each church. Sensors were placed at the height of a seated person $(1.10 \mathrm{~m})$ and thermal stratification was observed at a height of $8.5 \mathrm{~m}$. Thermal images were taken at controlled intervals of time and in different seasons in order to establish the evolution of thermal processes (Figure 2). 

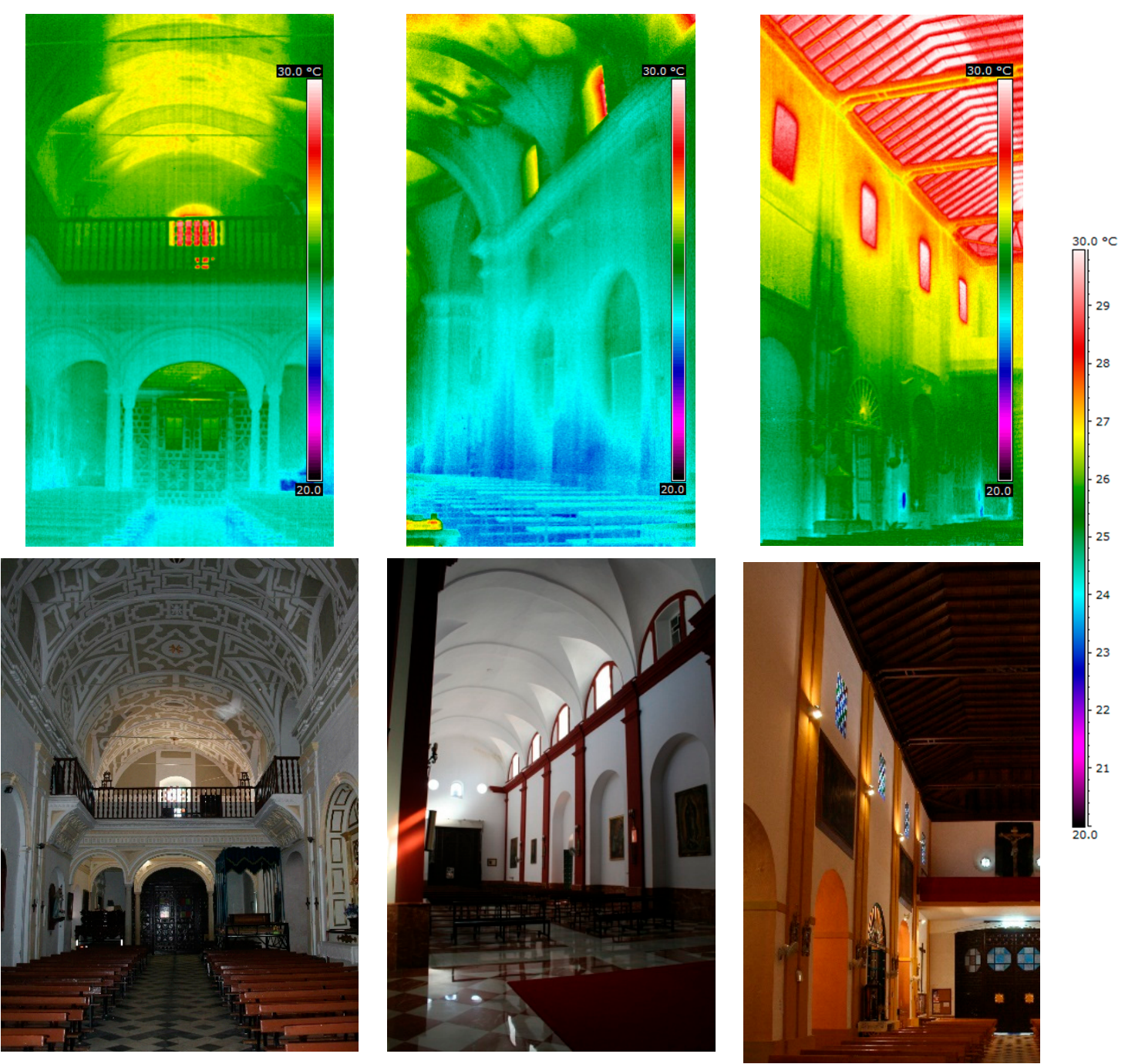

Figure 2. Surface Temperatures in June. (SF) San Francisco de Asís Church, (M) Nuestra Señora de la Merced Church, and (V) Nuestra Señora de la Victoria Church.

\subsection{Simulation Models}

The three-dimensional simulation models generated for each of the churches were validated using monitoring data. Each model reproduces the spatial volume of each church-including its environment and geometry-as well as its materials and climate (Figure 3). The model is validated comparing results with the temperature data $(\mathrm{T})$, relative humidity $(\mathrm{RH})$, and absolute humidity $(\mathrm{AH})$ recorded in situ over a year. Figure 4 shows the data and values for interior average temperature.
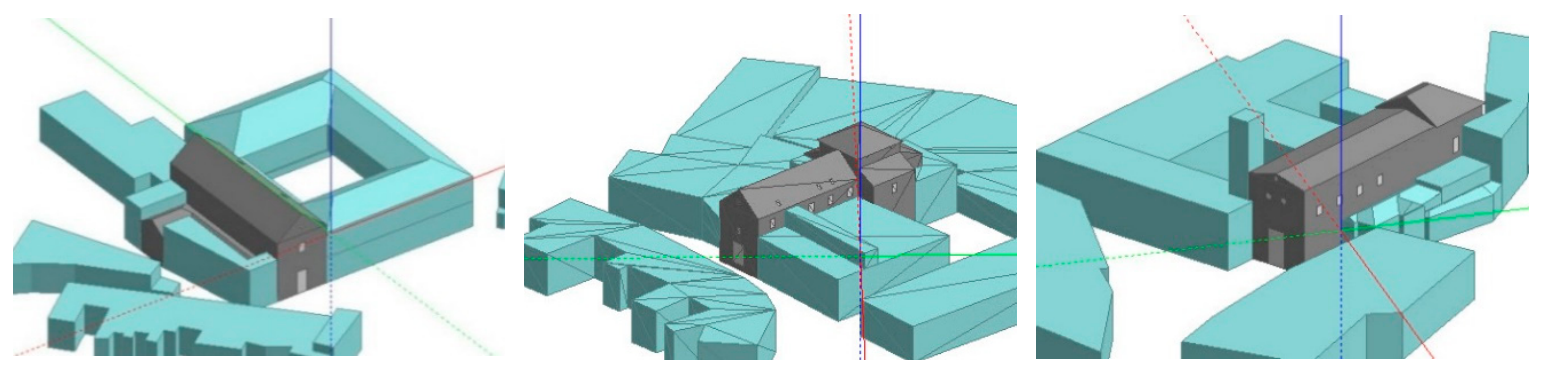

Figure 3. Simulation models. (SF) San Francisco de Asís Church, (M) Nuestra Señora de la Merced Church, and (V) Nuestra Señora de la Victoria Church. 


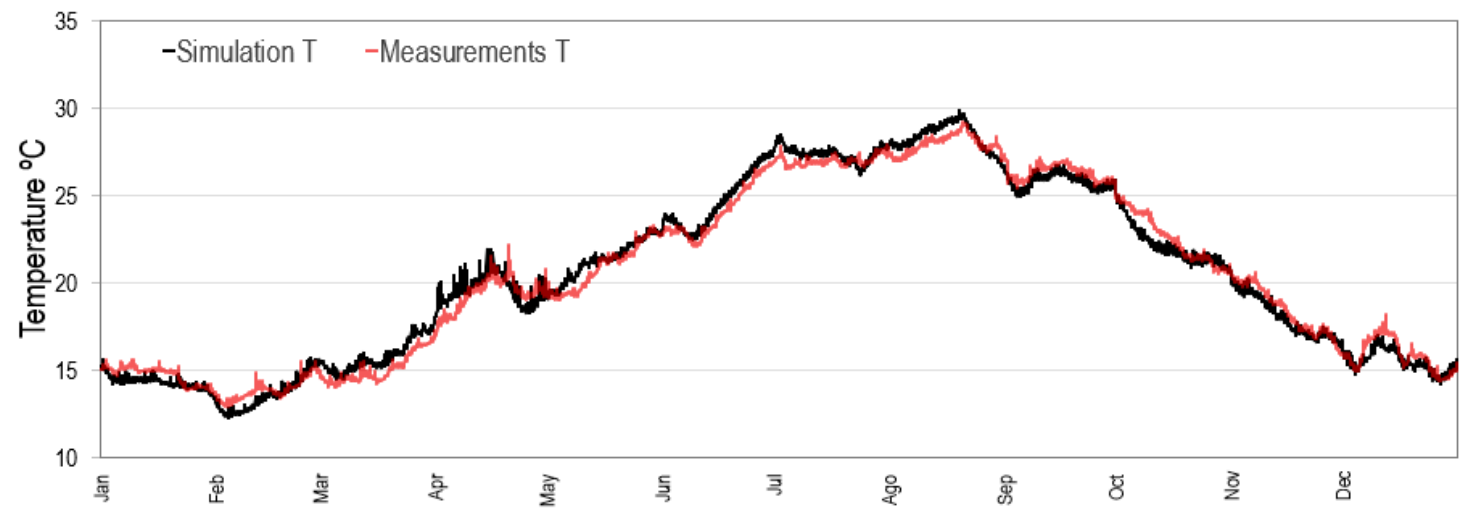

(SF) San Francisco de Asís Church

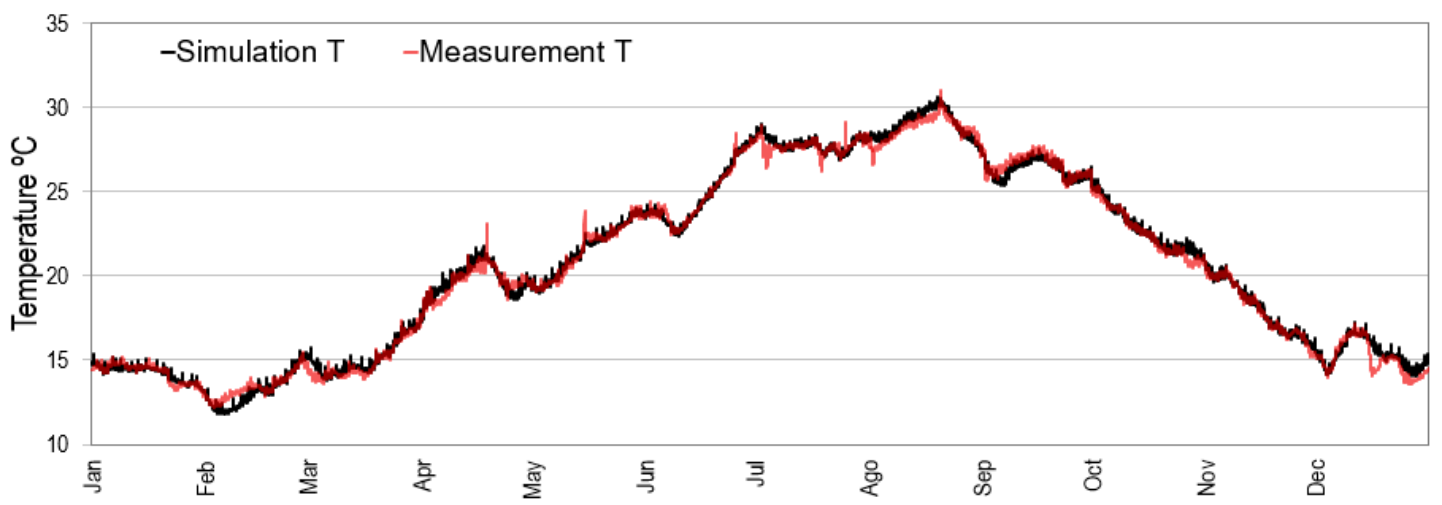

(M) № Señora de la Merced Church

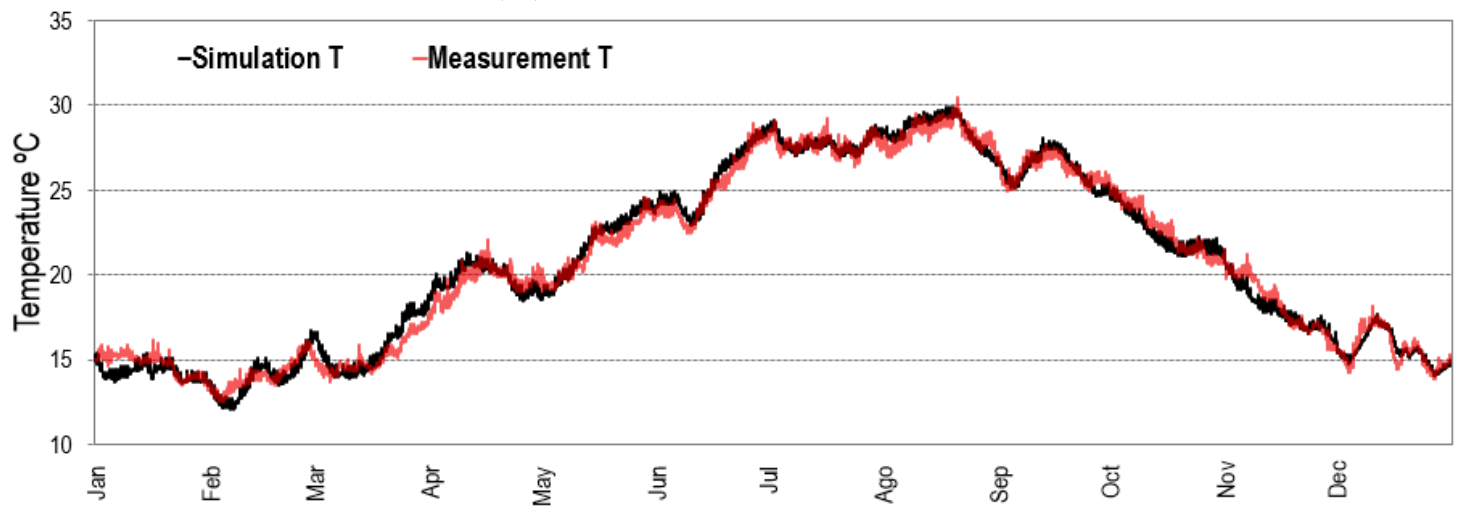

(V) № Señora de la Victoria Church

Figure 4. Validation temperature parameters.

Simulation models are considered validated when indicator Hourly Mean Bias Error MBE is $\leq 10 \%$ and Coefficient of Variation of the Root Mean Square Error (CV) RMSE $\leq 30 \%$. (Table 5).

Table 5. Results of statistical indicators.

\begin{tabular}{ccccc}
\hline PARAMETER & INDICATOR & SF & M & V \\
\hline \multirow{2}{*}{$\mathbf{T}$} & MBE & $-0.18 \%$ & $-0.21 \%$ & $-0.09 \%$ \\
& CV(RMSE) & $17.3 \%$ & $19.8 \%$ & $8.5 \%$ \\
\hline \multirow{2}{*}{ HR } & MBE & $-0.14 \%$ & $-0.25 \%$ & $-0.29 \%$ \\
& CV(RMSE) & $13.5 \%$ & $24.1 \%$ & $27.7 \%$ \\
\hline \multirow{2}{*}{ HA } & MBE & $-0.27 \%$ & $-0.29 \%$ & $-0.30 \%$ \\
& CV(RMSE) & $25.5 \%$ & $27.3 \%$ & $27.9 \%$ \\
\hline
\end{tabular}




\section{Results and Discussion}

Different hypotheses analyse the hygrothermal behaviour of the study samples with the application of active and combined environmental techniques, given that thermal comfort conditions and the preservation of heritage spaces cannot be guaranteed using passive techniques alone.

\subsection{Biological Degradation}

The current environmental conditions of the churches (without active systems or passive measures) were analysed to establish whether they encourage the development of biological degradation. In this case, no risk of biological deterioration is thought to exist when $\mathrm{T}$ values are $10-20{ }^{\circ} \mathrm{C}$ and $\mathrm{RH}<65 \%$. Low risk occurs with $\mathrm{T}$ values of $10-20{ }^{\circ} \mathrm{C}$ and $\mathrm{RH}>65 \%$ or $\mathrm{T}>20^{\circ} \mathrm{C}$ and $\mathrm{RH}$ $<65 \%$. There is a high risk of biological degradation when $\mathrm{T}>20^{\circ} \mathrm{C}$ and $\mathrm{RH}>65 \%$. Table 6 shows the percentage of time in each season where there is no risk, high risk, or low risk of biological degradation.

Table 6. Percentage of time with risk of biological deterioration.

\begin{tabular}{ccccc}
\hline \multirow{2}{*}{ SEASON } & & \multicolumn{3}{c}{ RISK } \\
\hline \multirow{3}{*}{ AUTUMN } & CHURCH & NO RISK & LOW & HIGH \\
& SF & $19 \%$ & $80 \%$ & $1 \%$ \\
& M & $24 \%$ & $74 \%$ & $2 \%$ \\
WINTER & V & $14 \%$ & $81 \%$ & $5 \%$ \\
& SF & $23 \%$ & $77 \%$ & $0 \%$ \\
& M & $25 \%$ & $75 \%$ & $0 \%$ \\
SPRING & V & $13 \%$ & $87 \%$ & $0 \%$ \\
& SF & $15 \%$ & $55 \%$ & $30 \%$ \\
& M & $20 \%$ & $73 \%$ & $7 \%$ \\
SUMMER & V & $6 \%$ & $69 \%$ & $25 \%$ \\
& SF & $0 \%$ & $88 \%$ & $12 \%$ \\
& $\mathbf{M}$ & $0 \%$ & $98 \%$ & $2 \%$ \\
& V & $14 \%$ & $81 \%$ & $5 \%$ \\
\hline
\end{tabular}

Analysis of the measurements obtained in the monitoring period shows how all churches, but especially those of San Francisco de Asís (SF) and Nuestra Señora de la Victoria (V), present an increase in biological degradation risk in spring and summer. Measurement data (air velocity and thermal images) show that the levels of ventilation in these churches are lower.

The impact of using the active and combined techniques featured in Table 1 was analysed in order to improve this situation of biological degradation in the churches. Tables 7-9 show the results of biological degradation of the different hypotheses (H1-H16) for each work operation $(24 \mathrm{~h}, 12 \mathrm{~h}$, use), season (winter (W), spring (Sp), summer (S) and autumn (A)). The tables show whether these techniques increase or decrease the risk. The results show that biological degradation does not occur in winter in any of the hypotheses, while the use of different active techniques improves the initial conditions. The results for active and combined environmental techniques with $\mathrm{T}$ control and $\mathrm{RH}$ systems simultaneously and permanently in use over 24-h (Table 7) or 12-h (Table 8) periods show that there is no risk of biological degradation in spring, summer, and autumn. The hypotheses that do not control RH (H1 (full air autonomous system (heating + cooling), H2 (air handling unit (AHU) (heating + cooling), and H6 (ventilation) present high risk).

This is not the case with buildings using environmental conditioning systems when there is an event (use operation, Table 9). The churches of San Francisco de Asís Church (SF) and Nuestra Señora de la Merced (M) show a high risk of biological degradation in spring, albeit with a small percentage of hours with low risk in both cases. Based on these results, it can be stated that active and combined systems can be considered suitable, except when they do not control RH. 
Table 7. Results of biological degradation risk with 24-h operation. Bold type (\% dates at high risk). Wd. double glazing F: floor insulation, V: barrel vault insulation, and W: blank insulation walls. AAS (full air autonomous system), AHU (air handling unit), HUMF (humidifier), RAD (heating with radiators), R.F (radiant flooring), and VENT (ventilation system).

\begin{tabular}{|c|c|c|c|c|c|c|c|c|c|c|c|c|c|c|c|c|c|}
\hline \multirow{3}{*}{ SEASON } & \multirow{3}{*}{ CHURCH } & \multirow{3}{*}{ H1 SAAS } & \multirow{3}{*}{$\mathrm{H} 2 \mathrm{AHU}$} & \multicolumn{2}{|r|}{$F$} & $W d+V+F$ & $W d+V+F+W$ & & $F$ & $W d+V+F$ & $W d+V+F+W$ & & $W d+V+F$ & $W d+V+F+W$ & $W d+$ & $+F+$ & \\
\hline & & & & \multicolumn{4}{|c|}{ AHU + HUMF } & \multicolumn{4}{|c|}{ AHU + RAD + HUMF } & \multicolumn{3}{|c|}{ AHU +R. F + HUMF } & \multicolumn{3}{|c|}{ VENT. + HUMF } \\
\hline & & & & H3 & $\mathrm{H} 8$ & H10 & H13 & $\mathrm{H} 4$ & H9 & H11 & H14 & H5 & H12 & H15 & H6 VENT & $\mathrm{H} 7$ & H16 \\
\hline \multirow{3}{*}{$w$} & $\mathrm{SF}$ & A & A & A & A & A & A & A & A & A & A & A & A & A & A & A & A \\
\hline & $\mathrm{M}$ & A & A & A & A & A & A & A & A & A & A & A & A & A & A & A & A \\
\hline & $\mathrm{V}$ & A & A & A & A & A & A & A & A & A & A & A & A & A & A & A & A \\
\hline \multirow{3}{*}{$S p$} & $\mathrm{SF}$ & B & B & A & A & A & A & A & A & A & A & A & A & A & B & A & A \\
\hline & $\mathrm{M}$ & C & C & A & A & A & A & A & A & A & A & A & A & A & c & A & A \\
\hline & $\mathrm{V}$ & B & в & A & A & A & A & A & A & A & A & A & A & A & C & A & A \\
\hline \multirow{3}{*}{$s$} & $\mathrm{SF}$ & B & C & C & A & A & A & A & A & A & A & A & A & A & C & A & A \\
\hline & $\mathrm{M}$ & C & C & A & A & A & A & A & A & A & A & A & A & A & C & A & A \\
\hline & V & B & C & A & A & A & A & A & A & A & A & A & A & A & C & A & A \\
\hline \multirow{3}{*}{$A$} & SF & C & C & A & A & A & A & A & A & A & A & A & A & A & C & A & A \\
\hline & $\mathrm{M}$ & B & C & A & A & A & A & A & A & A & A & A & A & A & C & A & A \\
\hline & $\mathrm{V}$ & B & C & A & A & A & A & A & A & A & A & A & A & A & C & A & A \\
\hline
\end{tabular}

A: No risk. B: Improvement of initial conditions although there is risk. C: Initial risk worsens. 
Table 8. Results of biological degradation risk with 12-h operation. Bold type (\% dates at high risk). Wd. double glazing, F: floor insulation, V: barrel vault insulation, W: blank insulation walls. AAS (full air autonomous system), AHU (air handling unit), HUMF (humidifier), RAD (heating with radiators), R.F (radiant flooring), and VENT (ventilation system).

\begin{tabular}{|c|c|c|c|c|c|c|c|c|c|c|c|c|c|c|c|c|c|}
\hline \multirow{3}{*}{ SEASON } & \multirow{3}{*}{ СHURCH } & \multirow{3}{*}{ H1 SAAS } & \multirow{3}{*}{$\mathrm{H} 2 \mathrm{AHU}$} & \multicolumn{2}{|r|}{$F$} & $W d+V+F$ & $W d+V+F+W$ & & $F$ & $W d+V+F$ & $W d+V+F+W$ & & $W d+V+F$ & $W d+V+F+W$ & \multirow[b]{3}{*}{ H6 VENT } & \multirow{2}{*}{\multicolumn{2}{|c|}{$\frac{W d+V+F+W}{\text { VENT. + HUMF }}$}} \\
\hline & & & & \multicolumn{4}{|c|}{ AHU + HUMF } & \multicolumn{4}{|c|}{ AHU + RAD + HUMF } & \multicolumn{3}{|c|}{ AHU + R. F + HUMF } & & & \\
\hline & & & & $\mathrm{H} 3$ & H8 & H10 & H13 & $\mathrm{H} 4$ & H9 & H11 & H14 & H5 & $\mathrm{H} 12$ & H15 & & H7 & H16 \\
\hline \multirow{3}{*}{$w$} & $\mathrm{SF}$ & A & A & $\mathrm{A}$ & $\mathrm{A}$ & A & A & $\mathrm{A}$ & $\mathrm{A}$ & A & $\mathrm{A}$ & $\mathrm{A}$ & A & $\mathrm{A}$ & A & A & $\mathrm{A}$ \\
\hline & $\mathrm{M}$ & A & A & A & A & A & A & A & A & A & A & A & A & A & A & A & A \\
\hline & $\mathrm{v}$ & A & A & A & A & A & A & A & A & A & A & A & A & A & A & A & A \\
\hline \multirow{3}{*}{$S p$} & $\mathrm{SF}$ & B & B & A & A & A & A & A & A & A & A & A & A & A & B & A & A \\
\hline & M & C & C & A & A & A & A & A & A & A & A & A & A & A & C & A & A \\
\hline & $\mathrm{v}$ & B & B & A & A & A & A & A & A & A & A & A & A & A & B & A & A \\
\hline \multirow{3}{*}{$s$} & SF & B & C & A & A & A & A & A & A & A & A & A & A & A & C & A & A \\
\hline & M & B & $\mathrm{C}$ & A & A & A & A & A & A & A & A & A & A & A & C & A & A \\
\hline & $\mathrm{V}$ & A & C & A & A & A & A & A & A & A & A & A & A & A & C & A & A \\
\hline \multirow{3}{*}{ A } & SF & C & C & A & A & A & A & A & A & A & A & A & A & A & C & A & A \\
\hline & M & B & C & A & A & A & A & A & A & A & A & A & A & A & C & A & A \\
\hline & $\mathrm{V}$ & B & C & A & A & A & A & A & A & A & A & A & A & A & C & A & A \\
\hline
\end{tabular}

A: No risk. B: Improvement of initial conditions although there is risk. C: Initial risk worsens.

Table 9. Results of biological degradation risk with operation use. Bold type (\% dates at high risk). Wd. double glazing, F: floor insulation, V: barrel vault insulation, W: blank insulation walls, AAS (full air autonomous system), AHU (air handling unit), HUMF (humidifier), RAD (heating with radiators), R.F (radiant flooring), and VENT (ventilation system).

\begin{tabular}{|c|c|c|c|c|c|c|c|c|c|c|c|c|c|c|c|c|c|}
\hline \multirow{3}{*}{ SEASON } & \multirow{3}{*}{ CHURCH } & \multirow{3}{*}{ H1 SAAS } & \multirow{3}{*}{$\mathrm{H} 2 \mathrm{AHU}$} & \multicolumn{2}{|r|}{$F$} & $W d+V+F$ & $W d+V+F+W$ & & $F$ & $W d+V+F$ & $W d+V+F+W$ & & $W d+V+F$ & $W d+V+F+W$ & \multirow[b]{3}{*}{ H6 VENT } & \multirow{2}{*}{\multicolumn{2}{|c|}{$\frac{W d+V+F+W}{\text { VENT. + HUMF }}$}} \\
\hline & & & & \multicolumn{4}{|c|}{ AHU + HUMF } & \multicolumn{4}{|c|}{ AHU + RAD + HUMF } & \multicolumn{3}{|c|}{ AHU + R. F + HUMF } & & & \\
\hline & & & & H3 & $\mathrm{H} 8$ & H10 & H13 & $\mathrm{H} 4$ & H9 & H11 & H14 & H5 & $\mathrm{H} 12$ & H15 & & H7 & H16 \\
\hline \multirow{3}{*}{$w$} & $\mathrm{SF}$ & A & A & A & A & A & A & A & A & A & $\mathrm{A}$ & $\mathrm{A}$ & A & A & $\mathrm{A}$ & A & A \\
\hline & $\mathrm{M}$ & A & A & A & A & A & A & A & A & A & A & A & A & A & A & A & A \\
\hline & $\mathrm{V}$ & A & A & A & A & A & A & A & A & A & A & A & A & A & A & A & A \\
\hline \multirow{3}{*}{$S p$} & $\mathrm{SF}$ & B & B & B & B & B & B & B & B & B & B & B & B & B & B & B & B \\
\hline & $\mathrm{M}$ & C & C & B & B & B & B & A & & B & B & B & B & B & $\mathrm{C}$ & A & B \\
\hline & $\mathrm{v}$ & B & B & A & A & A & A & A & A & A & A & A & A & A & B & A & A \\
\hline \multirow{3}{*}{$s$} & $\mathrm{SF}$ & B & C & B & A & A & & B & A & A & A & A & A & B & C & B & B \\
\hline & M & $\mathrm{C}$ & $\mathrm{C}$ & A & A & A & A & A & A & A & A & A & A & A & $\mathrm{C}$ & B & B \\
\hline & $\mathrm{V}$ & A & B & A & A & A & A & A & A & A & A & A & A & A & C & A & A \\
\hline \multirow{3}{*}{$A$} & SF & C & C & B & A & A & A & B & A & A & A & A & A & A & C & B & A \\
\hline & $\mathrm{M}$ & A & B & A & A & A & A & A & A & A & A & A & A & A & B & A & A \\
\hline & $\mathrm{V}$ & B & C & A & $\mathrm{A}$ & A & A & A & A & A & A & A & A & A & C & A & A \\
\hline
\end{tabular}




\subsection{Mechanical Degradation}

Tables 10 and 11 show the percentage of time when there is a risk of mechanical damage due to the deviation of $\mathrm{T}$ and $\mathrm{RH}$, depending on the operation use of the systems ( $24 \mathrm{~h}, 12 \mathrm{~h}$, and use) and hypotheses $(\mathrm{H})$ considered. A maximum deviation of $10 \%$ is established for $\mathrm{RH}$, while two deviation levels are set for $\mathrm{T}$, no risk (A) (limit $\pm 2{ }^{\circ} \mathrm{C}$ ), and moderate risk (B) (Limit $\pm 5^{\circ}$ ).

Table 10. Risk of mechanical degradation. Percentage of time where deviation limits are exceeded for Temperature (T) with different operation modes.

\begin{tabular}{cccccccccccccccccc}
\hline \multicolumn{1}{c}{$\boldsymbol{T}$} & & H1 & H2 & H3 & H8 & H10 & H13 & H4 & H9 & H11 & H14 & H5 & H12 & H15 & H6 & H7 & H16 \\
\hline \multirow{2}{*}{24} & SF & 0 & 0 & 0 & 0 & 0 & 0 & 0 & 0 & 0 & 0 & 0 & 0 & 0 & 2 & 20 & 17 \\
$H$ & M & 0 & 0 & 0 & 0 & 0 & 0 & 0 & 0 & 0 & 0 & 0 & 0 & 0 & 5 & 23 & 17 \\
& V & 0 & 0 & 0 & 0 & 0 & 0 & 0 & 0 & 0 & 0 & 0 & 0 & 0 & 4 & 30 & 20 \\
\hline \multirow{2}{*}{12} & SF & 15 & 17 & 15 & 11 & 12 & 7 & 15 & 12 & 12 & 8 & 10 & 10 & 7 & 2 & 12 & 8 \\
$H$ & M & 12 & 12 & 12 & 10 & 9 & 6 & 11 & 10 & 10 & 6 & 10 & 10 & 5 & 5 & 13 & 7 \\
& V & 15 & 15 & 15 & 12 & 11 & 6 & 12 & 12 & 10 & 5 & 12 & 10 & 5 & 4 & 23 & 15 \\
\hline \multirow{4}{*}{ USE } & SF & 3 & 3 & 3 & 6 & 4 & 4 & 4 & 7 & 6 & 5 & 5 & 6 & 5 & 1 & 3 & 2 \\
& M & 5 & 5 & 5 & 4 & 4 & 4 & 5 & 4 & 4 & 4 & 4 & 4 & 3 & 1 & 3 & 3 \\
& V & 6 & 6 & 6 & 7 & 10 & 6 & 6 & 7 & 7 & 4 & 7 & 6 & 5 & 2 & 7 & 5 \\
\hline
\end{tabular}

Table 11. Risk of mechanical degradation. Percentage of time where deviation limits are exceeded for Relative humidity $(\mathrm{RH})$ with different operation modes.

\begin{tabular}{|c|c|c|c|c|c|c|c|c|c|c|c|c|c|c|c|c|c|}
\hline \multicolumn{2}{|c|}{$R H$} & H1 & $H 2$ & H3 & H8 & H10 & H13 & $H 4$ & H9 & H11 & H14 & H5 & H12 & H15 & H6 & $H 7$ & H16 \\
\hline \multirow{3}{*}{$\begin{array}{l}24 \\
H\end{array}$} & SF & 25 & 30 & 0 & 0 & 0 & 0 & 0 & 0 & 0 & 0 & 0 & 0 & 0 & 37 & 0 & 0 \\
\hline & $\mathrm{M}$ & 23 & 30 & 0 & 0 & 0 & 0 & 0 & 0 & 0 & 0 & 0 & 0 & 0 & 37 & 3 & 2 \\
\hline & V & 23 & 30 & 0 & 0 & 0 & 0 & 0 & 0 & 0 & 0 & 0 & 0 & 0 & 36 & 6 & 3 \\
\hline \multirow{3}{*}{$\begin{array}{l}12 \\
H\end{array}$} & SF & 27 & 32 & 17 & 13 & 14 & 13 & 15 & 10 & 10 & 7 & 13 & 12 & 1 & 3 & 3 & 3 \\
\hline & $\mathrm{M}$ & 27 & 32 & 15 & 12 & 14 & 12 & 12 & 10 & 10 & 10 & 13 & 13 & 12 & 35 & 3 & 2 \\
\hline & $\mathrm{V}$ & 27 & 32 & 17 & 13 & 14 & 11 & 10 & 10 & 8 & 8 & 13 & 12 & 11 & 34 & 6 & 3 \\
\hline \multirow{3}{*}{ USE } & SF & 16 & 18 & 15 & 12 & 11 & 12 & 16 & 12 & 12 & 14 & 11 & 11 & 13 & 1 & 12 & 10 \\
\hline & $\mathrm{M}$ & 18 & 18 & 11 & 10 & 10 & 9 & 10 & 8 & 8 & 8 & 10 & 10 & 8 & 20 & 8 & 5 \\
\hline & V & 20 & 22 & 13 & 10 & 7 & 7 & 8 & 10 & 8 & 6 & 10 & 10 & 7 & 23 & 8 & 3 \\
\hline
\end{tabular}

Analysis carried out on the data shows that there is no risk of mechanical damage to the movable heritage of the sample if the active systems are in operation for $24 \mathrm{~h}$ (Tables 10 and 11). However, this does not happen in instances where systems do not control RH or where the church relies exclusively on ventilation (H1 (Full air autonomous system (heating + cooling), H2 (Air handling unit (AHU) (heating + cooling) H6 (Ventilation), H7 (Ventilation + humidifier), and H16 (H7 + HP6) ventilation +humid + window+ vault + walls + flooring) (Tables 10 and 11).

A major mechanical risk due to deviation of $\mathrm{T}$ (Table 10) is observed for active and combined systems in which only the ventilation and RH are controlled, including H6 (Ventilation), H7 (Ventilation + humidifier), and H16 (H7 + HP6). When the systems are in operation for 12-h periods, mechanical degradation occurs $10-15 \%$ of time, compared to $5-10 \%$ of the time when in operation solely when in use.

\subsection{Thermal Comfort}

Table 12 shows the percentage of time that comfort conditions are reached within the church, based on the data monitoring results. In the winter months, comfort conditions are not reached in the churches, whereas in summer they are observed in the churches for longer periods. The thermal comfort data averaged for a year are: winter (1\%), spring (56\%), autumn (73\%), and summer $(90 \%)$. 
Table 12. Percentage of time in comfort.

\begin{tabular}{ccccc}
\hline Seasons & Autumn & Winter & Spring & Summer \\
\hline SF & $72 \%$ & $0 \%$ & $35 \%$ & $98 \%$ \\
$\boldsymbol{M}$ & $75 \%$ & $2 \%$ & $77 \%$ & $83 \%$ \\
$\boldsymbol{V}$ & $74 \%$ & $1 \%$ & $58 \%$ & $89 \%$ \\
\hline
\end{tabular}

In the case of all study hypotheses, except those involving only ventilation thermal comfort conditions inside the churches, are met $100 \%$ of the time, when the systems are in use for $24-\mathrm{h}$ or 12 -h periods. For operation depending on use, the churches ensure comfort conditions during mass celebrations providing the systems (except ventilation systems) are switched on an hour before the event. However, operation depending on use does not guarantee occupants' comfort for the remaining hours of the day (Table 13).

In summer, the hypotheses that incorporate insulation in the church flooring significantly worsen comfort conditions (H8 (H3 + HP3) AHU + humidifier + insulated flooring), (H10 (H3 + HP5) AHU + humidifier + d.glazing + insul. vault+ insulated flooring), (H13 (H3 + HP6) AHU + humid. + window + vault + wall + flooring), (H9 (H4 + HP3) AHU + humidifier + radiators+ insulated flooring), (H11 (H4 + HP5) AHU + humid. + radiators + window + insul. Vault + insul.flooring), (H14 (H4 + HP6) AHU + humid. + radiators. + window + vault + walls + flooring), (H12 (H5 + HP5) AHU + humid. + rad. Flooring + window + in. vault + in.flooring), $(\mathrm{H} 15$ (H5 + HP6) AHU + humid. + rad. flooring + window + vault + walls + flooring), and (H16 (H7 + HP6) Ventilation + humid. + window + vault + walls + flooring). 
Table 13. Comfort. \% time of thermal comfort during the day (9:00 a.m.-9:00 p.m.) (Use operation). C comfort 100\% Wd. double glazing, F: floor insulation, V: barrel vault insulation, and $\mathbf{W}$ : blank wall insulation.

\begin{tabular}{|c|c|c|c|c|c|c|c|c|c|c|c|c|c|c|c|c|c|}
\hline & & & & & F & $W d+V+F$ & $\mathrm{Wd}+\mathrm{V}+\mathrm{F}+\mathrm{W}$ & & $\mathbf{F}$ & $W d+V+F$ & $\mathrm{Wd}+\mathrm{V}+\mathrm{F}+\mathrm{W}$ & & $W d+V+F$ & $W d+V+F+W$ & & & $W d+V+F+W$ \\
\hline & ON & H1 & $\mathrm{H} 2$ & H3 & H8 & H10 & H13 & H4 & H9 & H11 & H14 & H5 & H12 & H15 & H6 & H7 & H16 \\
\hline \multirow{3}{*}{ W } & SF & 43 & 42 & 32 & 38 & 47 & 54 & 32 & 62 & 40 & 38 & 41 & 40 & 50 & 12 & 2 & 9 \\
\hline & $\mathrm{M}$ & 41 & 33 & 33 & 40 & 39 & 46 & 32 & 41 & 41 & 47 & 39 & 38 & 46 & 23 & 8 & 14 \\
\hline & $\mathrm{V}$ & 56 & 56 & 55 & 56 & 59 & 66 & 56 & 57 & 61 & 62 & 55 & 59 & 65 & 30 & 15 & 17 \\
\hline \multirow{3}{*}{$\mathrm{Sp}$} & $\mathrm{SF}$ & 80 & 80 & 80 & 91 & 90 & 83 & 80 & 92 & 89 & 84 & 92 & 91 & 83 & 74 & 61 & 65 \\
\hline & $\mathrm{M}$ & 78 & 77 & 77 & 84 & 83 & 76 & 75 & 83 & 83 & 75 & 76 & 83 & 74 & 72 & 62 & 64 \\
\hline & $\mathrm{V}$ & 85 & 85 & 85 & 87 & 87 & 86 & 85 & 87 & 88 & 86 & 87 & 88 & 86 & 78 & 61 & 97 \\
\hline \multirow{3}{*}{$\mathrm{s}$} & $\mathrm{SF}$ & $\mathrm{C}$ & 97 & 99 & 36 & 45 & 75 & 98 & 36 & 46 & 45 & 37 & 43 & 73 & 89 & 98 & 71 \\
\hline & $\mathrm{M}$ & 86 & 86 & 86 & 43 & 45 & 72 & 78 & 43 & 43 & 72 & 87 & 44 & 72 & 78 & 86 & 60 \\
\hline & V & 96 & 96 & 99 & 50 & 54 & 82 & 99 & 50 & 55 & 83 & 45 & 50 & 83 & 78 & 95 & 83 \\
\hline \multirow{3}{*}{ A } & $\mathrm{SF}$ & 96 & 96 & 96 & 97 & C & C & 95 & 96 & $C$ & C & 96 & 99 & $\mathrm{C}$ & 95 & 92 & 99 \\
\hline & $\mathrm{M}$ & 99 & 99 & 99 & C & C & $\mathrm{C}$ & 90 & C & $\mathrm{C}$ & C & 98 & C & C & 98 & 92 & 98 \\
\hline & $\mathrm{V}$ & 96 & 96 & 96 & 93 & 96 & C & 93 & 93 & 95 & C & 92 & 94 & C & 94 & 79 & 94 \\
\hline
\end{tabular}




\subsection{Energy Consumption}

This study has assessed the energy consumption achieved through the application of different active environmental techniques and combined them to ensure the conditions of preservation and conservation of artworks and thermal comfort. In practically all case studies, the implementation of these techniques causes generally high energy consumption due to the large size and thermal inertia of these buildings (Figure 5).

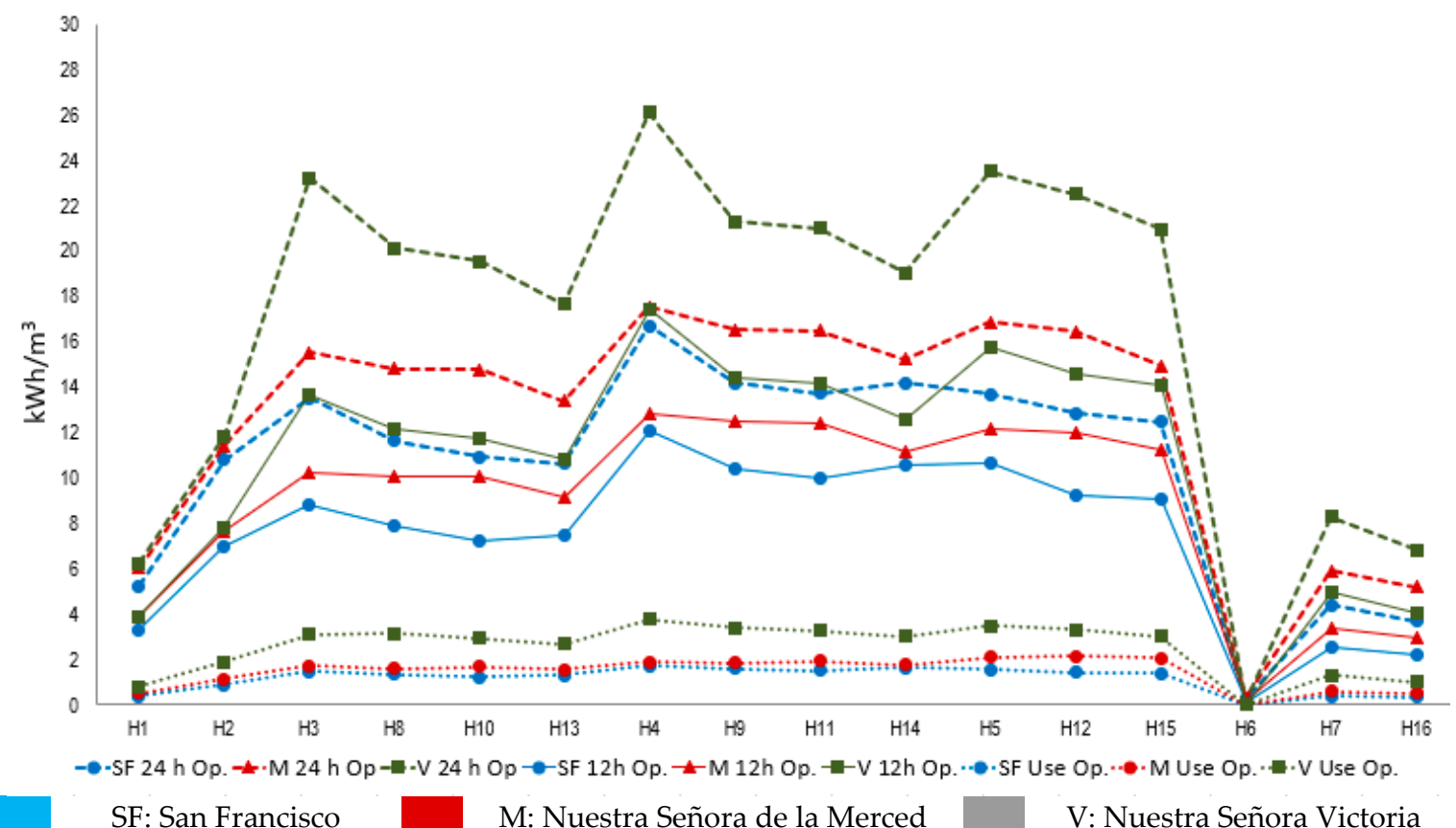

Figure 5. Annual consumption $\left(\mathrm{kWh} / \mathrm{m}^{3}\right)$.

Energy consumption ranges are $139 \mathrm{kWh} / \mathrm{m}^{2}$ (operating $24 \mathrm{~h}$ ), $98 \mathrm{kWh} / \mathrm{m}^{2}$ (operating $12 \mathrm{~h}$ ), and $15 \mathrm{kWh} / \mathrm{m}^{2}$ (operating use). According to the Basic Energy Saving Document (DB-HE) [28], energy consumption in this type of building is limited to $45-48 \mathrm{kWh} / \mathrm{m}^{2}$.

As is to be expected, the highest consumption occurs during the period of 24-h operation, and the lowest is found when systems are in use only during the celebration of religious events. Maximum annual consumption is around 120,500 kWh (operating $24 \mathrm{~h}$ ), while minimum consumption is about $10,000 \mathrm{kWh}$ (operating when in use). These values are an average value of the three churches.

Notable increases in energy consumption occur in spaces with minimal or non-existent air cavities in the roof. This is the case of the church of Nuestra Señora de la Victoria (V), which has no intermediate air chamber and has wooden coffering. There is no double roof, unlike in other churches with barrel vaults in which an air mass can be found between barrel vault and roof, muffling and reducing energy transfers.

As Table 14 shows, energy consumption in the operation of the different systems is not linear. Operating for $12 \mathrm{~h}$ reduces energy consumption by around $27-51 \%$ compared to doing so for $24 \mathrm{~h}$. In the case of operation, only when in use this consumption can be reduced by $90 \%$.

When combined environmental techniques were applied, energy savings were observed compared to active systems, with 24 -h operation reducing consumption by $10-23 \%$ and 12 -h operation offering a smaller reduction of $2-8 \%$. Finally, operation only when in use (events or religious acts) results in savings of $1-3 \%$. 
Table 14. Comparison of energy consumption maximum consumption $\mathbf{M}$ of church. Wd: double glazing, F: floor insulation, V: barrel vault insulation, and W: blank wall insulation.

\begin{tabular}{|c|c|c|c|c|c|c|c|c|c|c|c|c|c|c|c|c|}
\hline & & & & $\mathbf{F}$ & $\mathbf{W d}+\mathrm{V}+\mathrm{F}$ & $W d+V+F+W$ & & $\mathbf{F}$ & $\mathbf{W d}+\mathrm{V}+\mathrm{F}$ & $W d+V+F+W$ & & $\mathrm{Wd}+\mathrm{V}+\mathrm{F}$ & $\mathrm{Wd}+\mathrm{V}+\mathrm{F}+\mathrm{W}$ & & & $W d+V+F+W$ \\
\hline & H1 & $\mathrm{H} 2$ & H3 & H8 & H10 & H13 & $\mathrm{H} 4$ & H9 & H11 & H14 & H5 & H12 & H15 & H6 & H7 & $\mathrm{H} 16$ \\
\hline $24 \mathrm{~h}$ & $\mathbf{M}$ & M & M & $-10 \%$ & $-13 \%$ & $-2.3 \%$ & M & $-13 \%$ & $-14 \%$ & $-18 \%$ & M & $-4 \%$ & $-10 \%$ & $\mathbf{M}$ & M & $-16 \%$ \\
\hline $12 \mathrm{~h}$ & $-37 \%$ & $-3.4 \%$ & $-36 \%$ & $-38 \%$ & $-40 \%$ & $-44 \%$ & $-33 \%$ & $-37 \%$ & $-38 \%$ & $-38 \%$ & $-27 \%$ & $-33 \%$ & $-35 \%$ & $-46 \%$ & $-41 \%$ & $-51 \%$ \\
\hline Use & $-90 \%$ & $-91 \%$ & $-88 \%$ & $-88 \%$ & $-89 \%$ & $-89 \%$ & $-88 \%$ & $-88 \%$ & $-89 \%$ & $-89 \%$ & $-87 \%$ & $-88 \%$ & $-88 \%$ & $-94 \%$ & $-88 \%$ & $-91 \%$ \\
\hline
\end{tabular}




\subsection{Strengths and Limitations}

This paper presents the analysis and evaluation of various proposals for energy refurbishment of the three churches in which passive and active techniques will be used, compared, and appraised with respect to their effect on preservation, thermal comfort, and energy consumption. Three live case studies were used for the analysis, and these historic buildings were selected because they are of the same period and architectural style.

The opportunities for effective energy refurbishments techniques in each of these real case studies will depend upon many factors and need to be considered individually for each historic building. Thus, the solutions will vary, and not all of the hypotheses presented will be universally viable and will be applied on a case by case basis. The results of this research have not established implementation methods, but they identify the consequences of the solutions (hypotheses) if they were employed and the potential in energy reduction that they could provide. The proposed interventions may be considered only for churches without valuable wall artifacts and floors.

\section{Conclusions}

This study of the environmental conditions of churches has evaluated the influence of the implementation of active and combined (passive + active) systems in worship spaces in the Mediterranean climate of the south of Spain. The standards for artwork preservation and thermal comfort were applied to a historic building. Simulations were carried out for several possible scenarios for heating and cooling systems in the unheated church, and solutions were obtained for a current functional problem in which the techniques applied are presenting poor overall results as regards environmental quality and energy efficiency. Based on the methodology used, it can be stated that the proposals implemented for environmental refurbishment would improve the environmental conditions for the preservation of artworks, human comfort conditions, and energy consumption.

The use of combined techniques (active + passive) operating for 24 and $12 \mathrm{~h}$ improves the initial environmental conditions, reducing the degradation. In the case of ventilation systems or systems that do not control RH, the degradation worsens. If the systems function only when the building is occupied (in use), there is a minimum risk of bio-deterioration, particularly in spring.

24-h operation does not cause mechanical degradation of artworks, except in the case of systems that do not control RH or of ventilation systems. In addition, the percentage of time in which there is risk is higher with the operating $12 \mathrm{~h}$.

The churches are comfortable when the systems are in use for $24 \mathrm{~h}$ or $12 \mathrm{~h}$, except for ventilation systems. However, when not in operation, comfort conditions are not reached in the churches during the day, and comfort is only ensured when the systems are switched on at least one hour before events such as the celebration of mass.

The effects of combined techniques in the preservation of artworks are not conclusive, as the results are very similar to those obtained with active systems, and $\mathrm{RH}$ remains a problem in these spaces. Nevertheless, this technique has higher incidence on thermal comfort, because passive techniques result in a lower energy transfer and a more stable environment in these spaces.

Nevertheless, combined techniques including insulated church flooring can have negative repercussion on thermal comfort in summer, acting as a heatsink when outdoor temperature is at its highest. The highest transfers of energy are caused by the floors, and many of these spaces still have their original floors.

Energy consumption can be reduced by combining active and passive techniques, although the reduction is minimal in the case of operation when in use. Energy consumption increases with the systems which control RH. The 24-h and 12-h operation periods are better suited to the conservation of movable heritage than operating use. For thermal comfort all the operations are valid.

Of all the systems analysed, those supported by radiant floors or radiators cause less damage to the artworks, given the lower deviation of $\mathrm{T}$ and $\mathrm{RH}$. In general, these do not cause the churches to 
overheat, as these local systems heat the lower areas of the churches. These large buildings require the support of air systems in order to control environmental humidity values.

The greatest problem is energy consumption, given the large size of these historic buildings. Future research will explore other hypotheses, such as ventilation systems with control of RH during 24 or 12-h periods used in conjunction with local systems. This study about environmental techniques in historic buildings in the Mediterranean climate has contributed to earlier research and is validating a tool for optimising air quality and saving energy.

Finally, it can be stated that the use of these active and passive techniques alongside an operating regime of use is less harmful than if they were implemented in a cold climate.

Author Contributions: C.M. ${ }^{a}$ M.-G. and Á.L.L.-R. conceived and designed the experiments. C.M. ${ }^{a}$ M.-G. and Á.L.L.-R. performed the experiments. All authors analysed the data, and wrote, reviewed, and approved the final manuscript.

Funding: This research was funded by the Spanish government through the research and development projects "Energy Rehabilitation of tertiary buildings in Mediterranean climate by optimizing Solar Protection Systems" (ref BIA2014-53949-R).

Acknowledgments: The authors would like to thank the staff of the Department of the Built Environment, Eindhoven University of Technology for allowing us to collaborate with them in The Netherlands as part of the European Climate for Culture project. We would also like to thank the School of Architecture, Portsmouth University for allowing us to collaborate with research group CURe on a project on the Minimisation of Energy Loss, shrinking the footprint strategies. And the Department of Preventive Conservation of Instituto Andaluz de Patrimonio Histórico

Conflicts of Interest: The authors declare no conflict of interest. The funders had no role in the design of the study; in the collection, analyses, or interpretation of data; in the writing of the manuscript; or in the decision to publish the results.

\section{References}

1. General Directorate of Fine Arts and Cultural Artefacts. Preventive Conservation in Places of Worship; Spanish Cultural Heritage Institute, Ministry of Culture: Madrid, Spain, 2009.

2. Varas-Muriel, M.; Fort, R. Monitoring the thermal-hygrometric conditions induced by traditional heating systems in a historic Spanish church (12th-16th C). Energy Build. 2014, 75, 119-132. [CrossRef]

3. Turcanu, E.F.; Verdes, M.; Serbanoiu, I. Churches heating: The optimum Balance between cost management and thermal comfort. Procedia Technol. 2016, 22, 821-828. [CrossRef]

4. EN 15757. Conservation of Cultural Property-Specifications for Temperature and Relative Humidity to Limit Climate-Induced Mechanical Damage in Organic Hygroscopic Materials; BSI: London, UK, 2010.

5. EN 1579-1. Conservation of Cultural Property Indoor Climate-Part 1: Guidelines for Heating Churches, Chapel and other Places or Worship; BSI: London, UK, 2012.

6. Camuffo, D. Church Heating and the Preservation of the Cultural Heritage. Guider to the Analysis of the Pros and Cons of Various Heating Systems; Electa: Milano, Italy, 2006; ISBN 88-370-5034-8.

7. Magrini, A.; Franco, G. The energy performance improvement of historic buildings and their environmental sustainability assessment. J. Cult. Herit. 2016, 21, 834-841. [CrossRef]

8. Lucchi, E. Simplified assessment method for environmental and energy quality in museum buildings. Energy Build. 2016, 117, 216-229. [CrossRef]

9. Muñoz, C. Study of the Implantation of the Technologies of Hygrothermal Conditioning in the Refurbishment Project of Churches. The Case of Baroque Churches in Morón de la Frontera. Ph.D. Thesis, University of Seville, Seville, Spain, 15 September 2016. Available online: https:/ /idus.us.es/xmlui/handle/11441/47114 (accessed on 16 June 2017).

10. Fabbri, K.; Pretelli, M. Heritage buildings and historic microclimate without HVAC technology, Italy: Malatestiana Library in Cesena. UNESCO Memory of the World. Energy Build. 2014, 76, 15-31. [CrossRef]

11. Huijbregts, Z.; Kramer, R.P.; Martens, M.H.J.; van Schijndel, A.W.M.; Schellen, H.L. A proposed method to assess the damage risk of future climate change to museum objects in historic buildings. Build. Environ. 2012, 55, 43-56. [CrossRef] 
12. Muñoz-González, C.M.; León-Rodríguez, A.L.; Campano-Laborda, M.; Teeling, C.; Baglioni, R. The assessment of environmental conditioning techniques and the energy performance in historic churches located in Mediterranean climate. J. Cult. Herit. 2018. [CrossRef]

13. Balocco, C.; Colaianni, A. Assessment of energy sustainable operations on a historical building. The Dante Alighieri High School in Florence. Sustainability 2018, 6, 2054. [CrossRef]

14. Berardinis, P.; Rotilio, M.; Capannolo, L. Energy and Sustainable Strategies in the renovation of existing buildings: An Italian Case Study. Sustainability 2017, 9, 1472. [CrossRef]

15. Lucchi, E. Multidisciplinary risk-based analysis for supporting the decision making process on conservation, energy efficiency, and human comfort in museum buildings. J. Cult. Herit. 2016, 22, 1079. [CrossRef]

16. Directive 2010/31/EU of the European Parliament and of the Council of 19 May 2010. On the Energy Performance of Buildings; European Parliament, Council of the European Union: Brussels, Belgium, 2010; pp. 13-35.

17. ISO: 7726:1998. Ergonomic of the Thermal Environmet-Intruments for Measuring Physical Quantities; BSI: London, UK, 1998.

18. EN 15758:2010. Conservation of Cultural Property. Procedures and Instruments for Measuring Temperatures of the Air and the Surfaces of Objects; BSI: London, UK, 2010.

19. EN 13187:1998. Thermal Performance of Building-Qualitative Detection of Thermal Irregularities in Building Envelopes-Infrared Method; BSI: London, UK, 1998.

20. ISO 18434-1:2008. Condition Monitoring and Diagnostics of Machines. Thermography. Part 1: General Procedures; ISO: Geneva, Switzerland, 2008.

21. Design Builder-Simulation Made Easy. Available online: https:/ / www.ecoeficiente.es (accessed on 1 June 2018).

22. Muñoz-González, C.M.; León-Rodríguez, A.L.; Navarro, J. Air conditioning and passive environmental techniques in historic churches in Mediterranean climate. A proposed method to assess damage risk and thermal comfort preintervention, simulation-based. Energy Build. 2016, 130, 567-577. [CrossRef]

23. ASHRAE Guideline 14-2014: Measurement of Energy Demand and Water Savings; ASHRAE Standards Committee: Atlanta, GA, USA, 2014.

24. Spanish Thermal Building Regulations-Royal Decree 1027/2007, 20th of July 2007; The European Portal for Energy Efficiency in Buildings: Madrid, Spain, 2007.

25. Museums, Libraries and Archives. Heating, Ventilating and Air Conditioning Applications. s.l.: American Society of Heating, Refrigerating and Air-Conditioning Engineers; ASHRAE Standards Committee: Atlanta, GA, USA, 2007.

26. Erhardt, D.; Mecklenburg, M. Relative Humidity re-examined. In Preventive Conservation. Practice, Theory and Research, Preprints of the Ottawa Congress; International Institute for Conservation of Historic and Artistic Works: London, UK, 1994; pp. 32-38.

27. EN-ISO 7730. Ergonomics of the Thermal Environment-Analytical Determination and Interpretation of Thermal Comfort Using Calculation of the PMV and PPD Indices and Local Thermal Comfort Criteria; ISO: Geneva, Switzerland, 2005.

28. Spanish Technical Building Code, Basic Document Energy Saving; Ministerio de Fomento: Madrid, Spain, 2017.

(c) 2018 by the authors. Licensee MDPI, Basel, Switzerland. This article is an open access article distributed under the terms and conditions of the Creative Commons Attribution (CC BY) license (http:/ / creativecommons.org/licenses/by/4.0/). 